\title{
A Charge-Remote Allylic Cleavage Reaction: Mechanistic Possibilities
}

\author{
May Joy Contado and Jeanette Adams \\ Department of Chemistry, Emory University, Atlanta, Georgia, USA
}

Nancy J. Jensen and Michael L. Gross

Midwest Center for Mass Spectrometry, Department of Chemistry, University of Nebraska-Lincoln, Lincoln, Nebraska, IJSA

\begin{abstract}
The collision-induced allylic cleavage reactions of deuterium-labeled $[\mathrm{M}-\mathrm{H}+2 \mathrm{Li}]^{+}$and $[\mathrm{M}-\mathrm{H}]^{-}$ions of monounsaturated fatty acids were investigated. Three concerted mechanistic possibilities were considered for this process: a 14-elimination of a vinylic $\mathrm{H}$, a retro-ene reaction, and a 1,4-conjugate elimination. A fourth mechanistic possibility, a two-step radical version of the retro-ene and 1,4-conjugate elimination reactions, was also considered. The radical reactions are in accord with the isotopic labeling results and offer certain mechanistic consistencies for cleavage of both $\mathrm{C}-\mathrm{C}$ allyl bonds; they are expected, however, to have large activation energies. The lower-energy concerted alternatives, the retro-ene reaction for cleavage of the proximal and the 1,4-conjugate elimination for cleavage of the distal $\mathrm{C}-\mathrm{C}$ allyl bond, are also consistent with experimental results. The alternative of two different concerted mechanisms for cleavage of the two allyl bonds, however, is at odds with the charge-remote concept. (J Am Soc Mass Spectrom 1991, 2, 180-183)
\end{abstract}

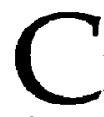

harge-remote fragmentations are analytically useful for structural determination of a large variety of biological and other molecules [1]. The reactions are also fundamentally interesting because they are believed to arise via mechanisms that are initiated by neither a charge nor a radical site [2, 3]. The original mechanism proposed for charge-remote losses of $\mathrm{C}_{n} \mathrm{H}_{2 n+2}(n>1)$ from both positive and negative closed-shell ions of saturated fatty acids, fatty alcohols, and picolinyl ester derivatives of fatty acids is a symmetry-allowed, concerted 1,4-elimination of $\mathrm{H}_{2}$. The reaction also produces neutral alkenes and terminally unsaturated, closed-shell fragment ions [2]. Analogous alkene and unsaturated ester production also accompanies thermolysis of fatty acid esters [4]. Newer evidence that strengthens the thermal analogy and supports the concertedness of the reactions is the charge-remote $O$-hydro- $C$-allyl elimination of heptaldehyde and the $\beta$-elimination of water from closed-shell $\beta$-hydroxy olefin-containing ions. These latter fragmentations have direct counterparts in neutral, thermolytic chemistry [3].

To augment our understanding of charge-remote fragmentations, we consider here the collision-induced allylic cleavage reactions of some monounsatu-

Address reprint requests to Jeanette Adams, Department of Chemistry, Emory University, 1515 Pience Drive, Atlanta, GA 30322. rated fatty acid $[\mathrm{M}-\mathrm{H}+2 \mathrm{Li}]^{+}$and $[\mathrm{M}-\mathrm{H}]^{-}$ions. The structurally useful allylic cleavages, which produce two abundant fragment ions (represented by peaks labeled $a$ and $b$ in Figure 1a), have not been previously investigated in mechanistic terms. Allylic cleavage proximal to the charge site of cis-9-octadecenoic acid $[\mathrm{M}-\mathrm{H}+2 \mathrm{Li}]^{+}$cations (Figure 1a) gives the $a$ ion of $m / z 141$, whereas cleavage distal from the charge site gives the $b$ ion of $m / z 195$. Cations of the analogue that is deuterated in the vinylic positions, cis-9-octadecenoic-9, 10- $d_{2}$ acid (Figure 1b), fragment also to give an $a$ ion of $m / z 141$. The $b$ ion, however, is now $2 \mathrm{u}$ higher in mass (of $m / z$ 197, Figure $1 b$ ).

Analogous to cis-9-octadecenoic acid cations, cis-7dodecenoic acid* cations (Figure 2a) decompose to give an $a$ ion of $m / z 113$ and a $b$ ion of $m / z$ 167. In contrast, cis-7-dodecenoic-4,4- $d_{2}$ acid cations (Figure $2 b$ ) instead decompose to given an $a$ ion of $m / z 114$ and $a b$ ion of $m / z$ 169. Cations of cis-7-dodecenoic$11,11-d_{2}$ acid (Figure 2c) fragment to give an $a$ ion of $m / z 113$ and $a b$ ion of $m / z$ 167. The $[\mathrm{M}-\mathrm{H}]^{-}$ anions of all these compounds fragment to give analogous closed-shell ions at $14 \mathrm{u}(2 \times \mathrm{Li})$ lower mass.

There are least four mechanisms whereby an allylic

*All reagents were commercially available except for cis-7dodecenoic-11,11- $d_{2}$ and cis-7-dodecenoic-4, 4- $d_{2}$ acids, which were synthesized as described earlier by Jensen [5]. 


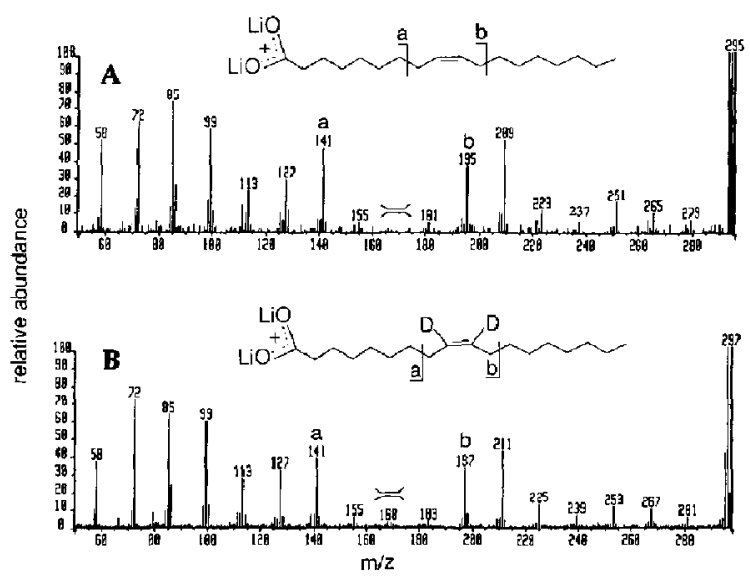

Figure 1. CID spectra of $[\mathrm{M}-\mathrm{H}+2 \mathrm{Li}]^{+}$ions of (a) cis-9-octadecenoic and (b) cis-9-octadecenoic-9,10- $d_{2}$ acids. Spectra were acquired by using $B / E$ linked scans and a VG $70-S$ mass spectrometer (Emory), as described elsewhere [3, 16]. Symbols for double bonds are shown where cleavages through the double bonds would give rise to fragment ions.
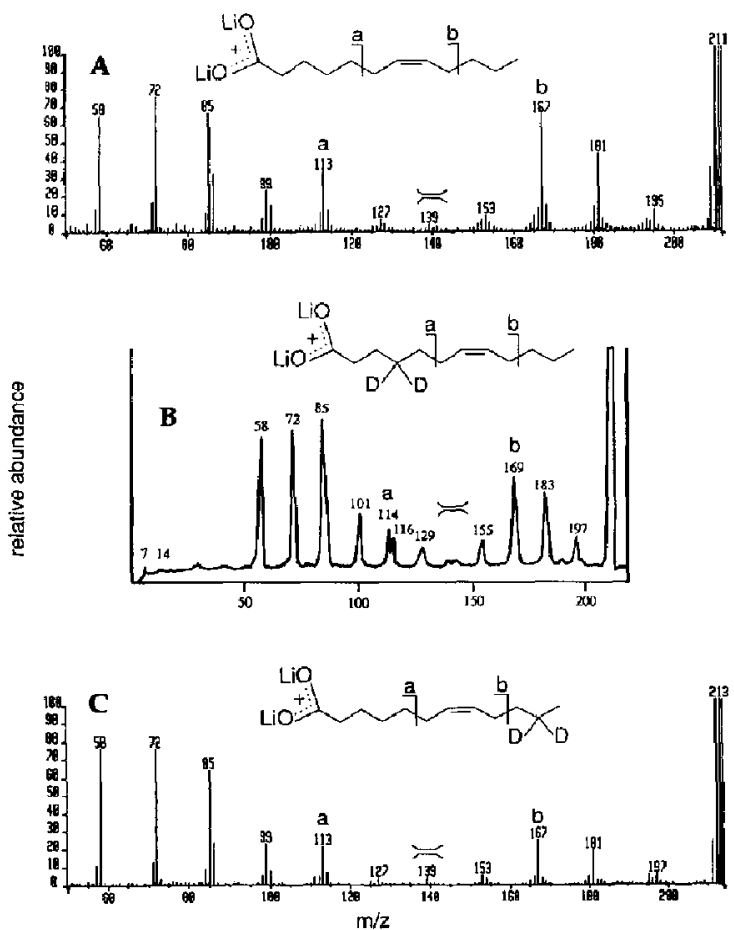

Figure 2. CID spectra of $[\mathrm{M}-\mathrm{H}+2 \mathrm{Li}]^{+}$ions of (a) cis-7dodecenoic, (b) cis-7-dodecenoic-4, 4- $d_{2}$, and (c) cis-7dodecenoic-11,11-d acids. Spectra in a and $c$ were acquired by using $B / E$ linked scans and a VG 70-5 mass spectrometer (Emory) [3, 16]. The spectrum in b was acquired by using a tandem Kratos MS-50 Triple Analyzer (Nebraska) [3] because low sample availability [5] coupled with low prectursor ion resolution in the $B / E$ linked scans did not give reliable results. Symbols for double bonds are shown where cleavages through the double bonds would give rise to fragment ions.

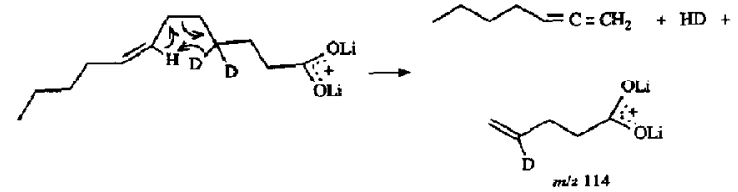

Scheme I

bond cleavage can occur. One is a 1,4-elimination of $\mathrm{H}_{2}$, which for allyl $\mathrm{C}-\mathrm{C}$ bond cleavage must involve transfer of a vinylic hydrogen (shown in Scheme I for cleavage proximal to the charge site of cis-7dodecenoic-4, 4- $\boldsymbol{d}_{2}$ acid cations). Thermal 1,4-eliminations of $\mathrm{H}_{2}$ in which three products are formed have activation energies of $-1.5-1.6 \mathrm{eV}$ and Arrhenius $A$ factors of $-10^{12} \mathrm{~s}^{-1}$. (See the preferred kinetic parameters for thermal 1,4-elimination reactions of chloroformates in ref. 6.) We question, however, whether the mechanism in Scheme I can account for the higher abundances of $a$ ions relative to other ions in the spectra. (Scheme I may not explain the high abundances of $a$ ions relative to other fragment ions formed by $1,4-\mathrm{H}_{2}$ eliminations elsewhere along the chain. That is, although transfer of a vinylic hydrogen in Scheme $\mathrm{I}$ is favored by $\sim 0.6 \mathrm{eV}$ over transfer of a secondary hydrogen, which occurs elsewhere along the alkyl chain, the $\Delta \mathrm{H}_{\mathrm{f}}$ of the neutral product allene in Scheme $\mathrm{I}$ is $\sim 1.69 \mathrm{eV}$ higher in energy than the $\Delta \mathrm{H}_{\mathrm{f}}$ of the neutral product alkenes that are formed elsewhere along the chain [7].) Moreover, this mechanism is inconsistent with the labeling results shown in Figure $1 \mathrm{~b}$. That is, a $1,4-\mathrm{H}_{2}$ elimination ta give $b$ ions, distal to the charge site, would necessitate loss of HD to give a product of $m / z 196$ instead of $m / z 197$, the latter of which is observed. From these considerations, we rule out $1,4-\mathrm{H}_{2}$ eliminations for the distal allyl bond cleavages. (It was previously suggested that the allylic cleavages involve double bond migrations via symmetry-forbidden 1,3-hydrogen shifts along with transfers of vinylic hydrogens via symmetry-allowed 1,4-climinations [8]. Such mechanisms also are not in accord with labeling results in Figure $1 \mathrm{~b}$, and we believe that it is highly unlikely that high-energy 1,3-shifts can account for the high relative abundances of the allylic cleavage product ions.)

Another mechanism is a retro-ene reaction (Scheme II, for cleavage proximal to the charge site of cis-7dodecenoic-4, 4- $d_{2}$ acid cations) [9]. Thermal retro-ene reactions occur for both cis- and trans- isomers of neutral molecules $[9 \mathrm{e}, \mathrm{f}]$ and have activation energies<smiles>[2H]C(=C)CCC([O])=[Ge]</smiles>

Scheme II 


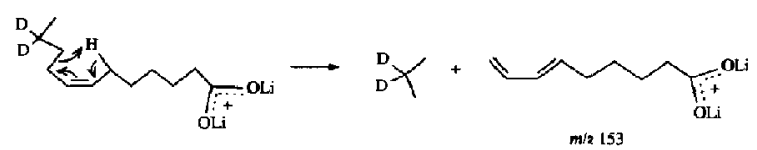

Scheme III

of $-1.2-1.5 \mathrm{eV}$ and $A$ factors of $\sim 10^{11} \mathrm{~s}^{-1}\left[9 \mathrm{~b}^{-}, \mathrm{c}\right]$ (Also see kinetic parameters for heteroatom retronene reactions of alcohols and acids in ref. 6.) A retro-ene reaction on the distal side of the double bond would also produce $b$ fragments that contain one double bond. This, however, is not observed experimentally. For example, unlabeled cis-7-dodecenoic acid cations (Figure 2a) fragment to give $b$ ions of $m / z 167$, which contain two double bonds, instead of the predicted $b$ ions of $m / z 169$. Thus, although the energetics are consistent with the relative ion abundances, the retroene reaction cannot be responsible for distal allyl cleavage even though it is consistent with labeling results for proximal allyl cleavage.

A third mechanistic possibility is a 1,4-conjugate elimination (Scheme III for cleavage distal to the charge site of $c i s-7$-dodecenoic-11,11- $d_{2}$ acid cations) [9a, 10]. Thermal 1,4-conjugate eliminations occur for hoth ris- and trans- isomers of neutral molecules [10a, b], and the activation energies are $-1.7-2.1 \mathrm{eV}$ and $A$ factors are $-10^{11} s^{-1}[10 c-e]$. Although this mechanism and its energetics from thermolysis chemistry are consistent with the products of distal allyl $\mathrm{C}-\mathrm{C}$ bond cleavages and all deuterium labeling results presented here, the most appropriate test compound (cis-7-dodecenoic-6,6- $d_{2}$ acid) has not yet been synthesized. This mechanism, however, does not account for the $a$ product ions formed by cleavage of the proximal allyl $C-C$ bond because saturated, instead of unsaturated, fatty acid $a$ ions would be predicted.

A fourth mechanistic possibility involves two-step reactions to give initially distonic radical ion intermediates (The original idea that radical intermediates are involved in the mechanism for loss of alkantes frum saturated fatty acid and other ions is credit to Wysocki et al.) [11]. They [12] also suggest that radical intermediates are involved in the allylic cleavage mechanisms originally presented by us [13] as concerted. (Other mechanisms that involve radical intermediates are proposed in detail, along with energetic considerations, in ref 1 , pp 166, 169, 176-177.) For distal cleavage to give $b$ ions, an allyl radical ion intermediate could first be formed by homolytic cleavage [6, 14], and it then could undergo a classic free-radical reaction to lose $\mathrm{H}$ - (see Scheme IV-A for cleavage distal to the charge site of cis-7-dodecenoic-11,11- $d_{2}$ acid cations). For allyl cleavage proximal to the charge site, a somewhat similar mechanism that by necessity involves instead a saturated, as opposed to allyl, distonic radical ion can be envisioned (see Scheme IV-B for cleavage proximal to the charge site of cis-7dodecenoic-4,4- $d_{2}$ acid cations). Thermal radical reac-

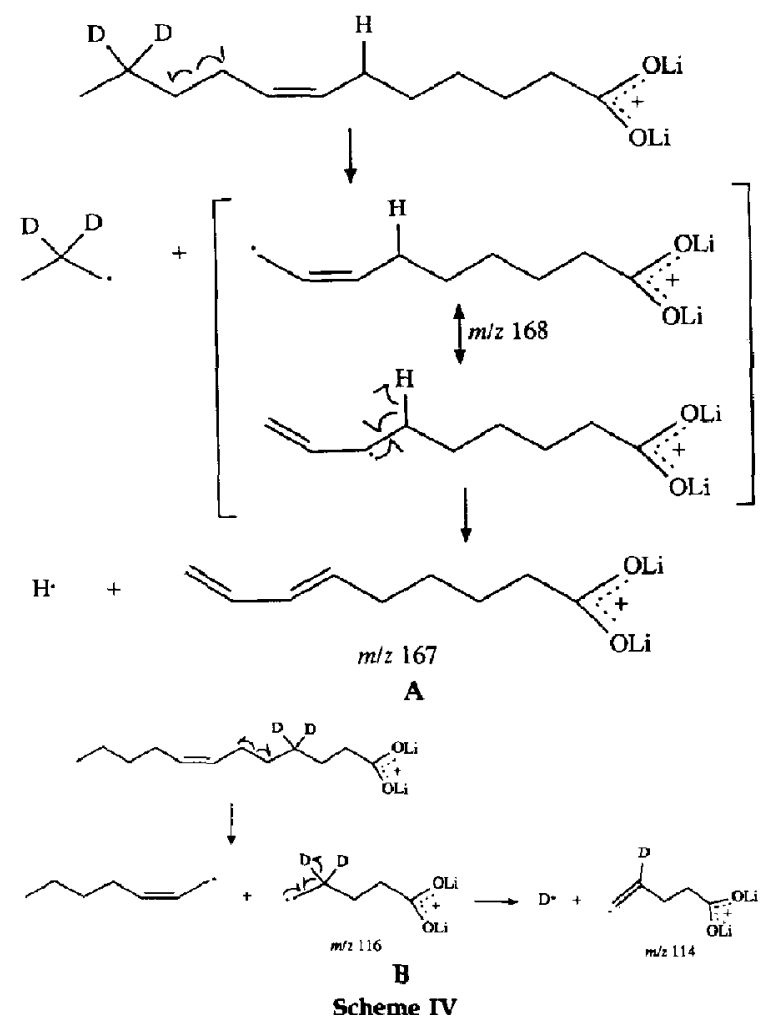

tions that involve homolytic $C-C$ bond cleavages have overall activation energies of $\sim 5-6 \mathrm{eV}$ and $A$ factors of $\sim 10^{14}-10^{17} \mathrm{~s}^{-1}[14]$.

One difficulty with the two radical reactions presented in Scheme IV is the expectcd large activation energies. As discussed in greater detail elsewhere [1], we do not expect such high-energy homolytic $\mathrm{C}-\mathrm{C}$ bond cleavages to compete effectiveily with other reactions, such as heterolytic loss of alkali cation, that also occur in the time scale of the collision-induced dissociation (CID) experiments. Activation energies of $\sim 5-6 \mathrm{eV}$ are also not in accord with center-of-mass energies of $1.4-2.5 \mathrm{eV}$ [15] and $1.6 \mathrm{eV}$ [11], at which the less abundant charge-remote losses of $\mathrm{C}_{n} \mathrm{H}_{2 n+2}$ have been reported. A second difficulty is that the allyl radical intermediate of $m / z 168$ shown in Scheme IV-A should be more stable by at least $0.95 \mathrm{eV}$ [14b], and thus significantly more abundant, than its saturated counterpart of $m / z 116$ shown in Scheme IV-B. It is clear from Figures $1 a$ and $b$ and $2 a$ and $c$ that this is not the case. (The greater abundance ratio of $\mathrm{m} / \mathrm{z}$ $116 / 114$ [ $d$-labeled; Figure $2 b$ ] vs. $m / z$ 114/113 [unlabeled; Figure 2a] can be understood from a primary isotope effect, which would attenuate the abundance of the ion of $m / z 114$, no matter whether it is produced by a two-step radical reaction or by a one-step elimination. Also, it should be noted that highly abundant radical ions, which would correspond to the allyl radicals shown in Scheme IV-A, are formed from 
acid $\left[\mathrm{M}-\mathrm{H}^{-}\right.$anions and from acid, ester, and alcohol $[\mathrm{M}+\mathrm{Li}]^{+}$cations. They are noticeably, and currently inexplicably, absent from the spectra of the dilithiated acids. Further research is being performed to address this phenomenon.)

The equally unsettling alternative to the two-step radical processes is that of different concerted mechanisms for severing the distal and the proximal $\mathrm{C}-\mathrm{C}$ allyl bonds. For example, we have not ruled out distal allyl $\mathrm{C}-\mathrm{C}$ bond cleavage via a 1,4-conjugate elimination (a one-step version of the two-step radical process in Scheme IV-A), nor proximal $\mathrm{C}-\mathrm{C}$ bond cleavage via the retro-ene mechanism (a one-step version of the two-step process in Scheme IV-B). If these two different concerted mechanisms pertain to cleavage of the two allyl bonds, the process cannot be entirely "charge-remote". A charge-remote process should be mechanistically identical irrespective of whether the allyl bond is distal or proximal to the charge site. The lack of mechanistic consistency, if true, may point to a stabilizing interaction of the charge site and the terminal unsaturation(s) of the resulting fragment ions, lowering the activation energies for the retro-ene reaction for the proximal allyl cleavage and the 1,4-conjugate elimination for the distal. Resolution of these matters awaits further studies, which are currently being conducted.

\section{Acknowledgments}

This work was supported in part by the Emory University Research Fund; by the Petroleum Research Fund, which is administered by the American Chemical Society; and by the Midwest Center for Mass Spectrometry, a National Science Foundation Regional Instrumentation Facility (CHE-8620177). We also acknowledge funding from NIH (S10-RR0-2478) for the use of the VG 70-S mass spectrometer as a shared instrument. A preliminary report of this data was presented at the 37th ASMS Conference on Mass Spectrometry and Allied Topics, May, 1989, Miami Beach, Florida.

\section{References}

1. Adams, J. Mass Spectrom. Rev. 1990, 9, 141.
2. (a) Jensen, N. J.; Tomer, K. B.; Gross, M. L. J. Am. Chem. Soc. 1985, 107, 1863. (b) Adams, J.; Gross, M. L. J. Am. Chem. Soc. 1986, 108, 6915. (c) Adams, J.; Gross, M. L. Anal. Chem. 1987, 59, 1576. (d) Deterding, L. J.: Gross, M. L. Anal. Chim. Acta 1987, 200, 431.

3. Adams, J.; Gross, M. L. J. Am. Chem. Soc. 1989, 111, 435.

4. Sun, K. K.; Hayes, H. W.; Holman, R. T. Org. Mass Spectrom. 1970, 3, 1035.

5. Jensen, N. J. Ph.D. Thesis, University of Nebraska-Lincoln, Lincoln, NE, 1986.

6. Benson, S. W.; O'Neal, H. E. Kinetic Data on Gas Phase Unimolecular Reactions; NSRDS-NBS 21; U.S. Government Printing Office: Washington, D.C. 1970.

7. Lias, S. G.; Bartmess, J. E.; Liebman, J. F.; Holmes, J. L.; Levin, R. D.; Mallard, W. G. I. Phys. Chem. Ref. Data 1988. 17. Suppl. no. 1 .

8. Bambagiotti, A. M.; Coran, S. A.; Vincieri, F. F.; Petruccianti, T.; Traldi, P. Org. Mass Spectrom. 1986, 21, 485.

9. (a) March, J. Advanced Organic Chemistry, 3rd ed.; Wiley: New York, 1985; pp 896-941, 1014-1020. (b) Ellis, R. J.; Frey, H. M. J. Chem. Soc. 1964, 5578. (c) Smith, G. G.j Blau, S. E. 1. Phys. Chem. 1964, 68, 1231. (d) Hoffmann, H. M. R. Angert. Chem. Int. Ed. 1969, 8, 556. (e) Roth, W. R. Chimia 1966, 20, 229. (f) Blomquist, A. T.; Taussig, P. R. J. Am. Chem. Soc. 1957, 79, 3505.

10. (a) Greenwood, F. L. J. Org. Chem, 1959, 24, 1735. (b) Greenwood, F. L. I. Org. Chem. 1962, 27, 2308. (c) Wellington, C. A.; Walters, W. D. J. Am. Chem. Soc. 1961, 83, 4888. (d) Frey, H. M.; Krantz, A.; Stevens, I. D. R. J. Chem. Soc. 1969, A, 1734. (e) Loudon, A. G.; Maccoll, A.; Wong, S. K. J. Am. Chem. Soc. 1969, 91, 7577.

11. Wysocki, V. H.; Ross, M. M.; Horning, S. R.; Cooks, R. G. Rapid Commur. Mass Spectrom. 1988, 2, 214.

12. Wysocki, V. H.; Ross, M. M. Int. J. Mass Spectrom. Ion Processes, in press.

13. Contado, M. J.; Adams, J.; Jensen, N. I.; Gross, M. L. Proceedings of the 37 th ASMS Conference Mass Spectrometry and Alited Topics 1989, 654.

14. (a) Kerr, J. A. In Free Radicals, vol. 1; Kocki, J. K., Ed.; Wiley: New York, 1973; pP 1-36. (b) Doering, W. V. E.; Roth, W. R. Angew. Chem. Int. Ed. 1963, 2, 115.

15. Cody, R. B. Rapid Commun. Mass Spectrom. 1988, 2, 260.

16. (a) Teesch, L. M.; Adams, J. I. Am. Chern. Soc. 1990, 112, 4110. (b) Teesch, L. M.; Adams, J. J. Am. Chem. Soc., in press. (c) Contado, M. J.; Adams, J. Anal. Chim. Acta, in press. (d) Contado, M. J.; Adams, J.; Gross, M. L. Adv. Mass Spectrom. 1989, 118, 1034. 